\title{
Estimation of Specific Gravity with Penetration and Penetration Index Parameters by Artificial Neural Network
}

\author{
Sercan Serin ${ }^{1}$, Sebnem Karahancer ${ }^{2}$, Ekinhan Eriskin ${ }^{2}$, Nihat Morova ${ }^{2}$, Mehmet Saltan $^{2}$, Serdal Terzi $^{2}$ \\ ${ }^{1}$ Departement of Civil Engineering, Duzce University \\ ${ }^{2}$ Departement of Civil Engineering, Suleyman Demirel University
}

\section{Article Info \\ Article history: \\ Received May $25^{\text {th }}, 2017$ \\ Revised June $14^{\text {th }}, 2017$ \\ Accepted June $16^{\text {th }}, 2017$ \\ Keyword: \\ Artifical neural network \\ Specific gravity \\ Penetration \\ Penetration index}

\begin{abstract}
Specific Gravity of the bitumen changes according to the ambient temperature. Different specific gravity values can be calculated at different temperature. Estimating models like Artificial Neural Network - ANN could be very useful to obtain the specific gravity value uniform. Specific gravity values obtained from Long-Term Pavement Performance - LTPP were estimated with artificial neural networks. Penetration and Penetration Index of binder were used for estimating the specific gravity of the bitumen. As a result, ANN get $84 \%$ of R2 between obtained and estimated values.
\end{abstract}

\section{Corresponding Author:}

Sercan Serin, Departement of Civil Engineering, Duzce University, Duzce University, Faculty of Technology, D Blok, 81620, Duzce, TURKEY. Email: sercanserin@duzce.edu.tr

\section{Introduction}

Current practices for asphalt mix design and acceptance testing rely on volumetric properties. Vital to the calculation of mix volumetric properties are specific gravity measurements of the mixture and the aggregate in the mixture. Superpave mix design is getting popular day to day and more recognized by researchers. The volumetric analyses provide the basis for the Superpave mix design method. Specific gravity of the materials is essential to calculate the volume of the mixture.

Specific Gravity of the bitumen changes according to the ambient temperature. Different specific gravity values can be calculated at different temperature. Estimating models like Artificial Neural Network - ANN could be very useful to obtain the specific gravity value uniform.

Pavement researchers have been widely using ANNs in diverse subjects during the past decade. ANNs have been successfully used by researchers to predict/back- calculate pavement moduli by training the ANNs using deflection data from falling-weight deflectometers [1-3]. Tutumluer and Seyhan [4] estimated the horizontal and shear moduli by using confining and deviator stresses of triaxial test, deformation and aggregate properties. Lacroix et al. [5] used the resilient moduli data to predict the dynamic modulus master curve of asphalt mixtures. Some researchers predicted the fatigue life of pavements with ANN-based methods [6-7]. Tarefder et al. [8] used ANNs to predict permeability of asphalt mixtures by using mixture variables such as air voids, grain size, saturation and effective asphalt-to-dust ratio.

Several researchers also developed models to determine the severity and type of the cracks with the help of ANN [9-12]. 
In this study, Specific gravity values obtained from Long-Term Pavement Performance - LTPP [13] were estimated with artificial neural networks. Penetration and Penetration Index of binder were included to the model.

\section{Materials and Method}

Data used in this paper is obtained from Long-Term Pavement Performance - LTPP [13]. For modelling these, penetration, penetration index and specific gravity data are get from the program. It's tried to obtain a relation between these parameters using ANN.

For predicting the specific gravity value of bitumen using ANN models, an appropriate selection of input parameters (neurons) is essential. There are two nodes in the input layer corresponding to two variables: penetration and penetration index of the bitumen. Model summary was seen in Table 1.

Table 1. ANN Model for specific gravity

\begin{tabular}{l|l|l|l|l}
\hline Inputs & Number of Neuron & Number of Layers & Model & Output \\
\hline $\begin{array}{l}\text { Penetration } \\
\text { Penetration Index }\end{array}$ & $30-20-10$ & 3 & $(2-30-20-10-1)$ & Specific Gravity \\
\hline
\end{tabular}

\section{Research Findings}

The relationship between obtained predicted values and measured values using the developed ANN model is shown in Figure 1. As it is illustrated in this figure, the predicted values are very close to experimental results, and this indicates a strong correlation between the input and output parameters of the ANN model. The $\mathrm{R}^{2}$ values that are used to determine the significance of the ANN model.

From all parameters, $80 \%$ of parameters were selected as set of training randomly and the rest was selected as set of test (20\%). Also the model was verified and tested. As seen from the Figure 1, training parameters were estimated as $100 \%$, validation parameters were estimated as $98,6 \%$, test parameters splitted by model were estimated as $98,5 \%$ and the all parameters were estimated as $92 \%$ of regression value by the model.
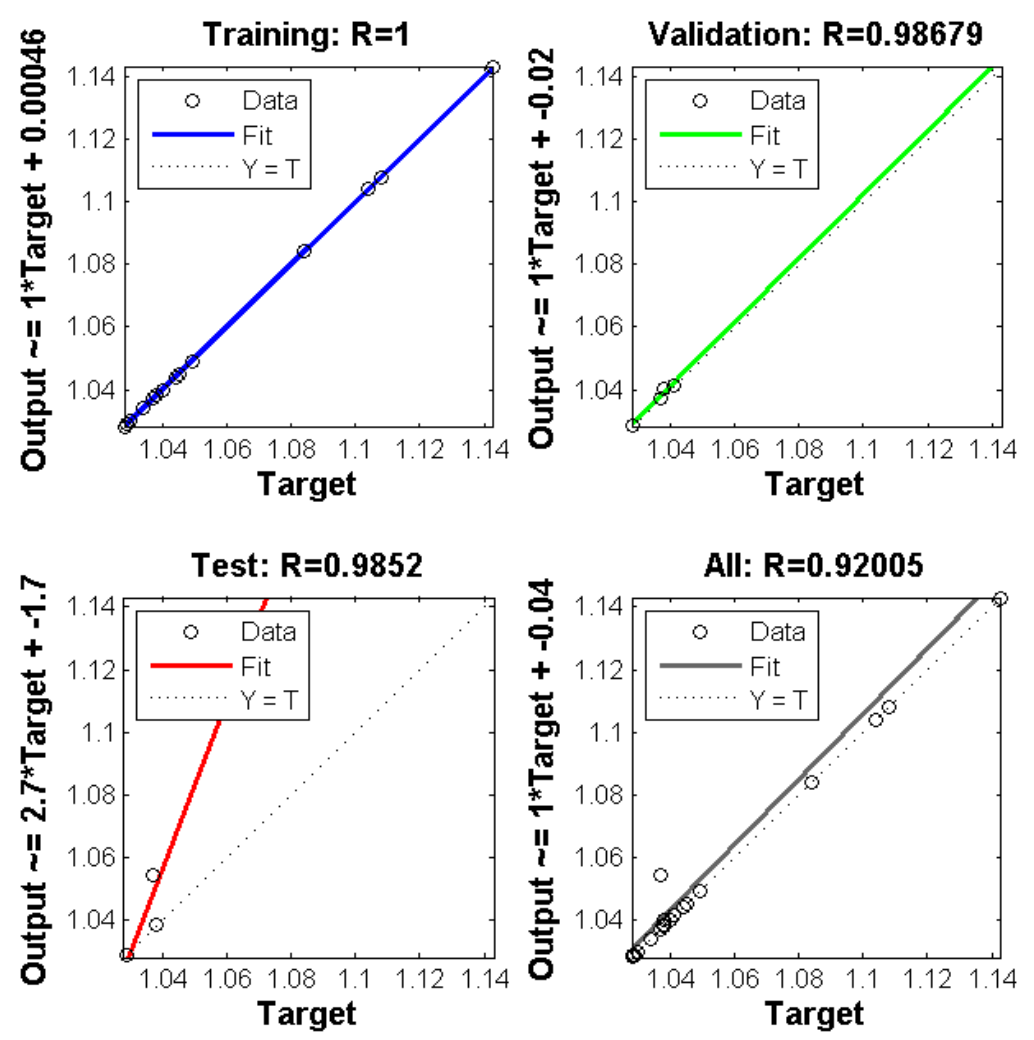

Figure 1. Relationship between the actual and predicted values by ANN for training data, validation data, testing data, and all data. 
Input parameters of test parameters were given to the model after the model was trained successfully and output parameters were predicted. Obtained estimation results were compared to the real test results (Figure 2). Model predicted the test parameters successfully with $\mathrm{R}^{2}$ value of $84 \%$.

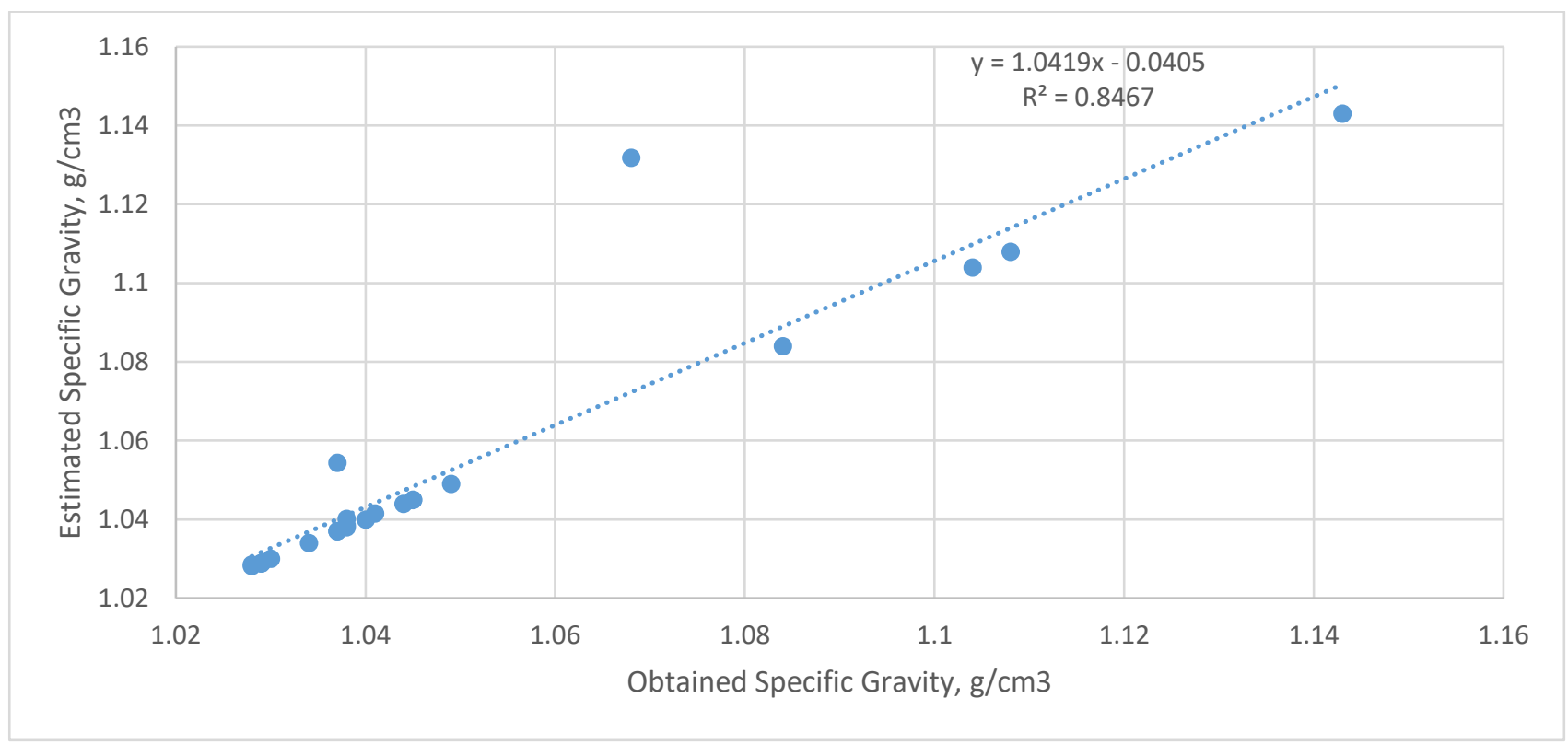

Figure 2. $\mathrm{R}^{2}$ graph for test parameters of model

\section{Results}

In this study, an ANN method was developed to model the specific gravity of the bitumen for varying penetration and penetration index values of the bitumen. The ANN model predicted the test parameters successfully with regression value of $98 \%$. The result indicates that the proposed model can be applied in estimating specific gravity of bitumen. The model is further applied to evaluate the effect of different values of penetration and penetration index on specific gravity.

\section{References}

[1] Y. Kim and R. Kim, "Prediction of layer moduli from falling weight deflectometer and surface wave measurements using artificial neural network." Transportation Research Record: Journal of the Transportation Research Board, 1639, 53-61, 1998.

[2] H. Ceylan, K. Gopalakrishnan and A. Guclu, "Advanced approaches to characterizing nonlinear pavement system responses." Transportation Research Record: Journal of the Transportation Research Board, 2005 (1), 86-94, 2007.

[3] A. Guclu and H. Ceylan, "Condition assessment of composite pavement systems using artificial neural net- works-based rapid backcalculation algorithms." TRB 86th annual meeting compendium of papers CD-ROM, 2007.

[4] E. Tutumluer and U. Seyhan, "Neural network modeling of anisotropic aggregate behavior from repeated load triaxial tests." Transportation Research Record: Journal of the Transportation Research Board, 1615, $86-93,1998$.

[5] A. Lacroix, Y.R. Kim and S.R. Ranjithan, "Back- calculation of the dynamic modulus from the resilient modulus of asphalt concrete using an artificial neural network." Transportation Research Record: Journal of the Transportation Research Board, 2057 (1), 107-113, 2007.

[6] C. Huang, Y.M. Najjar and S.A. Romanoschi, "Predicting asphalt concrete fatigue life using artificial neural network approach.” In: Transportation Research Board Annual Meet- ing. Washington, DC, 2007. 
[7] F. Xiao, A. Amirkhanian and C.H. Juang "Prediction of fatigue life of rubberized asphalt concrete mixtures contain- ing reclaimed asphalt pavement using artificial neural networks." Journal of Materials in Civil Engineering, 21 (6), 253 - 261, 2009.

[8] R.A. Tarefder, L. White and M. Zaman, "Neural network model for asphalt concrete permeability." Journal of Materials in Civil Engineering, 17 (1), 19-27, 2005.

[9] M.S. Kaseko and S.G. Ritchie, "A neural-network based methodology for pavement crack detection and classifi- cation.” Transportation Research Part C: Emerging Technol- ogies, 1 (4), 275-291, 1993.

[10] S. Owusu-Ababio, "Effect of neural network topology on flexible pavement cracking prediction." Computer-Aided Civil and Infrastructure Engineering, 13, 349-355, 1998.

[11] Z., Lou, et al., "Application of neural network model forecast short-term pavement crack condition: Florida case study.” Journal of Infrastructure Systems, 7 (4), 166-171, 2001.

[12] B.J. Lee and H.D. Lee, "A robust position invariant artificial neural network for digital pavement crack analysis.” In: Transportation Research Board Annual Meeting. Washington, DC, 2003.

[13] FHWA, 2016, “Long Term Pavement Performance” Federal Highway Administration. 